\title{
RECYCLING OF CONSTRUCTION WASTE USING HIGH-SPEED MILLING PROCESS: DETERMINATION OF WASTE CONCRETE
}

\author{
ZdeněK Prošek ${ }^{a, b, *}$, Pavel Tesárek ${ }^{a}$, Jan Trejbal ${ }^{a}$, Tereza Horová ${ }^{a}$ \\ ${ }^{a}$ Czech Technical University in Prague, Faculty of Civil Engineering, Thákurova 7, 166 29 Prague, Czech \\ Republic \\ ${ }^{b}$ Czech Technical University in Prague, University Centre for Energy Efficient Buildings, Třinecká 1024, 27343 \\ Buštěhrad, Czech Republic \\ * corresponding author: zdenek.prosek@fsv.cvut.cz
}

\begin{abstract}
This paper deals with the use of high-speed milling process for recycling old concrete and direct determination of the potential of input waste. For this purpose, three different types of waste concrete were used: prefabricated railway sleeper, structural concrete of monolithic pillar and prefabricated drainage gutter. The paper directly examines the chemical and phase composition by XRF, X-Ray Diffraction (XRD), Energy Dispersive X-ray Spectrometry (EDS) and microscopic analysis, particle size distribution and $\mathrm{pH}$ of the recycled material. Results of those analysis are used to select suitable recycled material. The suitability of choice is supported by mechanical tests of 28-day old cement pastes, where the compressive strength and dynamic modulus of elasticity are observed properties. Specimens measuring $40 \times 40 \times 160 \mathrm{~mm}$ are composed of $70 \mathrm{wt} . \%$ Portland cement and rest is micronized concrete. In all cases, the results are compared with the reference material.
\end{abstract}

KEYWORDS: Recycling, concrete waste, cement composites, XRD, XRF, mechanical properties.

\section{INTRODUCTION}

Construction produces the largest amount of waste from all sectors, for example in the EU, construction waste is almost $33 \%$ of the 2.5 billion tons of waste generated [1]. There is an effort to recycle this waste and reduce its storage on dumps according to the EU directive. Nowadays, ca. $90 \%$ of waste is recycled and the remaining $10 \%$ is stored at the dumps [2]. Concrete is the most used construction material and therefore sources of concrete recyclate are relatively large and easily accessible. However, due to different properties of old concrete, the production and consequently the quality of the recyclate differ greatly. The most important aspects that affect the final quality of recyclate are: the type of use of old concrete and thus the recipe (the quality of cement and aggregate), the age of concrete and the method of care (prefabricate, monolith). There are two main areas in the construction sector, from which the concrete recyclate is obtained, the road construction and the civil engineering. The highest level of recycling is in the field of road construction because the existing road construction can be processed directly on site using mobile recycling units and reused in the construction of a new one [3, 4. In other cases, the old concrete is taken to a landfill or recycling facility. Materials from recycling lines are most often used as coarse or fine aggregates in new concrete or in stabilizing layers [5, 6]. In this way, only coarse fractions are processed. In the case of a very fine fraction (grain size below $1 \mathrm{~mm}$ ), there is still no ideal solution to allow its use on a wider scale. Several possible directions of application of this material are examined in cement composites [7+[10] for example as thermally activated binder replacement [11], as mixtures for cement production [12] or as a part of geopolymers based binders [13. Due to high demands on energy consumption and $\mathrm{CO}_{2}$ production the most sophisticated and environmentally friendly method is when very fine fraction of recycled concrete is used in its raw form. For this reason, the paper deals with the possibility of mechanical activation of concrete recyclate with high-speed milling. Thus treated concrete may be used without other energy-intensive treatment or without auxiliary additives. Mechanical activation of the recyclate occurs when hydrated cement paste is grinded and this reveal still unhydrated grains of clinker. This is primarily $\mathrm{C}_{2} \mathrm{~S}$ which reacts in the long run. The amount of unhydrated clinker is directly dependent on the type of cement and the age of the concrete. In general, the amount in the cement matrix can be estimated between 10 to $20 \%$, that 10 $-20 \mathrm{wt} . \%$ of recyclate can form a binder in the future composite and the remaining amount will form a filler. Recyclate not only reduces the amount of cement but also the amount of natural filler in future concrete [14, 15].

\section{MATERIALS AND SAMPLES}

The research investigated three old types of concrete that were recycled to finely ground concrete powder using high-speed milling. The first finely ground concrete recyclate was obtained from the PB2 and the SB8 railway sleepers. These sleepers had been roughly crushed first and then metal components and 
reinforcement were separated. In this way, a coarse concrete recyclate, fraction $0-32 \mathrm{~mm}$, was obtained from which the fraction $0-16 \mathrm{~mm}$ was separated and then milled.

The second finely ground recyclate was obtained from concrete drainage gutter which did not contain reinforcement and therefore the individual damaged fittings were crushed and milled. Just as in the case of sleepers, this is a prefabricated product with the difference that the concrete drainage gutter is considerably younger than sleepers that are from 10 to 50 years old and are made of aggregate and cement with worse properties.

The last (third) material is finely ground concrete column. These columns are from monolithic structure, where waste was generated during the reconstruction of the existing hall of the canceled factory Walter Motors which was founded by Josef Walter in 1911. The recycling process was dealt with in this material and was therefore divided into two investigated materials. The recycling process was optimized and large amount of the original filler was removed for the column A, because high-speed milling was applied only to the fraction $0-1 \mathrm{~mm}$ that originated after crushing coarse fraction of recyclate on small-volume wedge mill. The second column was the column B, which was also made of concrete recyclate fraction $0-$ $16 \mathrm{~mm}$.

These input materials were also investigated with reference Portland cement CEM I 42.5R from Radotín area.

From these materials the samples were additionally made for testing micromechanical properties. Tested materials contained 70 wt.\% of Portland cement CEM I $42.5 \mathrm{R}$ and $30 \mathrm{wt} . \%$ of finely ground concrete recyclate. Water ratio was equal to 0.35. For each recyclate a kit was created which contained five specimens with dimensions $40 \times 40 \times 160 \mathrm{~mm}$. The second day after production, the specimens were demoulded and kept in $100 \%$ humidity, the temperature was 22 $\pm 1{ }^{\circ} \mathrm{C}$ during 28 days.

\section{EXPERIMENTAL METHODS}

To select the suitability of individual recyclates, a set of experimental methods were selected to describe the suitability of the material for its subsequent use. These methods include X-ray fluorescence analysis (XRF) for detecting the amount of inappropriate (foreign) substances, $\mathrm{pH}$ measurements for finding alkalinity of recyclates, granulometry for finding the effect of high-speed milling, XRD for determination of amount of clinker materials and electron microscopy. The suitability of selection was supported by mechanical tests of 28 days old cement pastes.

$\mathrm{X}$-ray fluorescence analysis (XRF) is a method based on secondary $\mathrm{X}$-ray radiation and its output is a line spectrum in which the number of pulses per second is displayed for the respective wavelengths or respective energies. From this spectrum the weighting of individual elements is then calculated. Elemental analysis by XRF spectrometer was performed on a SPECTRO XEPOS (Spectro CS s. R.) Instrument. The $\mathrm{pH}$ was determined from aqueous extracts (in a weight ratio of $1: 100)$ after 24 hours at room temperature $\left(25 \pm 1{ }^{\circ} \mathrm{C}\right.$ ) to $\mathrm{pH}$ meter (from Monokrystaly a.s.). This type of $\mathrm{pH}$ meter is suitable for fast measurement with a deviation of about 0.2 degrees. To determine fraction of finely ground powder after the micromilling process and to determine the size of the medium grain a laser granulometer was used, the socalled dry method was used. For the determination of particle morphology and microscopic structural and elemental analysis a scanning electron microscope with the Schottky cathode FEG SEM Merlin ZEISS was used, which is located in the Laboratory of Electron Microscopy and Microanalysis at the University Center of Energy Efficient Buildings. Qualitative and quantitative analysis of the chemical composition of the samples was performed using an X-ray microanalysis, namely a Oxford Instruments Energy Spectrometer (EDS).

Nondestructive resonance method was used to measure dynamic modules. The Brüel \& Kjaer measuring set consists of the Brüel \& Kjær type 3560-B-120, the Brüel \& Kjær type 4519-003 acceleration sensor, the Brüel \& Kjær type 8206 impact hammer and the control laptop. Compressive strength was determined using a Heckert, a model FP100 (hydraulic press). Compressive strength was determined by a one-shot pressure test. Testing was controlled by shifting at a constant velocity of $0.3 \mathrm{~mm} / \mathrm{s}$.

\section{Results AND Discussion}

Table 1 summarizes X-ray fluorescence analysis results. The table lists the elements, respectively. their oxides, which were present in a concentration above $1 \mathrm{wt.} \%$. The results compare individual samples of micronized recyclates with reference portland cement CEM I 42.5R Radotín. None of these recyclables contain excessive amounts of harmful substances. In columns A and B samples, there is a clear difference in the amount of $\mathrm{Si}$, which is the percentage of siliceous sand by about $8 \mathrm{wt} . \%$. The presented results also showed that samples contained increased content of iron which is caused by type of milling during which the gear wheel is worn. LOI means immeasurable elements such as carbon and hydrogen. The most interesting part of the results is the amount of $\mathrm{CaO}$ because it indicates the amount of unhydrated clinker and C-S-H gel. The best properties has the column $\mathrm{A}$, the drainage gutter and the railway sleeper.

In another measurement, pH was measured. Both recyclates and reference cement were used as samples. The resulting $\mathrm{pH}$ of the reference cement was 12.6. The resulting values of the recyclates themselves range from 11.5 to $12.6 \mathrm{pH}$. The results show that none of the recycled material will reduce the alkalinity of the mixture and thus negatively affect the hydration. 


\begin{tabular}{lrrrrr}
\hline \multirow{2}{*}{ Oxides } & \multicolumn{5}{c}{ Percent weight of individual oxides [\%] } \\
\cline { 2 - 6 } & Cement & Sleeper & Gutter & Column A & Column B \\
\hline $\mathrm{SiO}_{2}$ & 17.16 & 40.53 & 66.54 & 36.35 & 44.49 \\
$\mathrm{CaO}$ & 66.67 & 21.09 & 22.18 & 23.80 & 16.37 \\
$\mathrm{Al}_{2} \mathrm{O}_{3}$ & 3.68 & 11.79 & 22.18 & 7.56 & 10.66 \\
$\mathrm{Fe}_{2} \mathrm{O}_{3}$ & 3.43 & 4.10 & 6.37 & 3.13 & 3.64 \\
$\mathrm{MgO}$ & 2.35 & 2.29 & 3.93 & 1.42 & 2.03 \\
$\mathrm{~K}_{2} \mathrm{O}$ & 0.67 & 1.83 & 4.52 & 1.45 & 1.64 \\
$\mathrm{Na}_{2} \mathrm{O}$ & 2.97 & 1.51 & 4.32 & 1.35 & 1.84 \\
$\mathrm{SO}_{3}$ & 4.96 & 1.21 & 1.06 & 1.57 & 1.19 \\
$\mathrm{LOI}$ & 3.08 & 15.63 & 3.95 & 23.34 & 18.11 \\
\hline
\end{tabular}

TABLE 1. Results of XRF analysis.

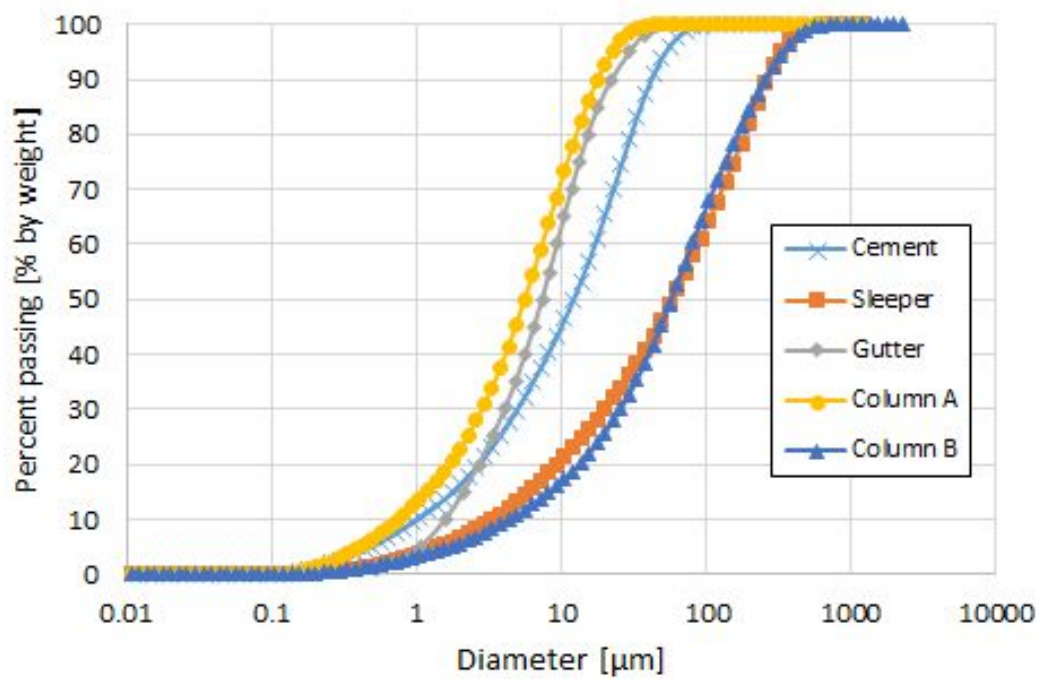

FiguRE 1. Grain curves for cement and individual samples of recyclates.

Figure 1 compares typical granulometric curves of reference cement and individual recycled materials. Recyclates from the gutter and the column A have a finer grain curve than reference cement (Radotín). In contrast, sleepers and the column B are thicker than reference cement. It can be assumed that the recyclates from the gutter and column A will be more reactive whereby we can expect higher amount of unhydrated clinker grains.

Figure 2 shows a record of XRD analysis with individual peaks (extremes) belonging to the respective phases. The clinker minerals $\mathrm{C}_{3} \mathrm{~S}$ and $\mathrm{C}_{2} \mathrm{~S}$ have basically 5 strong peaks from 32.3 to 34.4 (Figure 2), of which the peak at $32.65,33.25$ and 34.4 are $\mathrm{C}_{3} \mathrm{~S}$ and $\mathrm{C}_{2} \mathrm{~S}$ only, or are not significantly affected other phases. Peak at 32.65 labeled " $\mathrm{C}_{3} \mathrm{~S}$ and $\mathrm{C}_{2} \mathrm{~S}$ " is basically the only one given by the $\mathrm{C}_{3} \mathrm{~S}$ and $\mathrm{C}_{2} \mathrm{~S}$ phases. To calculate the representation of individual clinker materials, a peak 32.65 was used because it is basically different and is composed only of these phases. For Portland cement CEM I 42.5R, the amount of clinker minerals $\mathrm{C}_{3} \mathrm{~S}$ and $\mathrm{C}_{2} \mathrm{~S}$ was $90 \% \pm 5 \%$. In the case of samples gutter and sleeper, the peak at 32.65 is not visible. It means that there is not more than $1 \%$ of
$\mathrm{C}_{3} \mathrm{~S}$ and $\mathrm{C}_{2} \mathrm{~S}$. In case of column $\mathrm{A}$, peaks are visible at $35.65,33.25$ and 34.4 but is not visible at 33.25. The results showed that the column A and column B contain clinker grains. Amount of clinker is larger for the sample from column A. Namely, the sample from the column A contained approx. 6.3 wt.\% unhydrated clinker and the sample from column B 4.5 wt.\%.

Table 2 shows the results from an electron microscope analysis where 100 grains were measured for each material and elemental analysis was performed for each grain and the grain size was measured. From the elemental analysis, phases were subsequently derived by stoichiometry. High speed milling produses grains in one direction, so the shape index was created, therefore the ratio of the widest part of the grain to the narrowest. Results showed that the aggregate formed from quartz provides a larger grain size, moreover, grains during milling are not so unidirectional.

The results of the previous five analysis showed the most suitable material for recycling the column A, the column with a larger part of the aggregate removed. To confirm this assumption, mechanical tests were carried out. Results of these tests are shown in Figure 3 The results of the compressive strength 


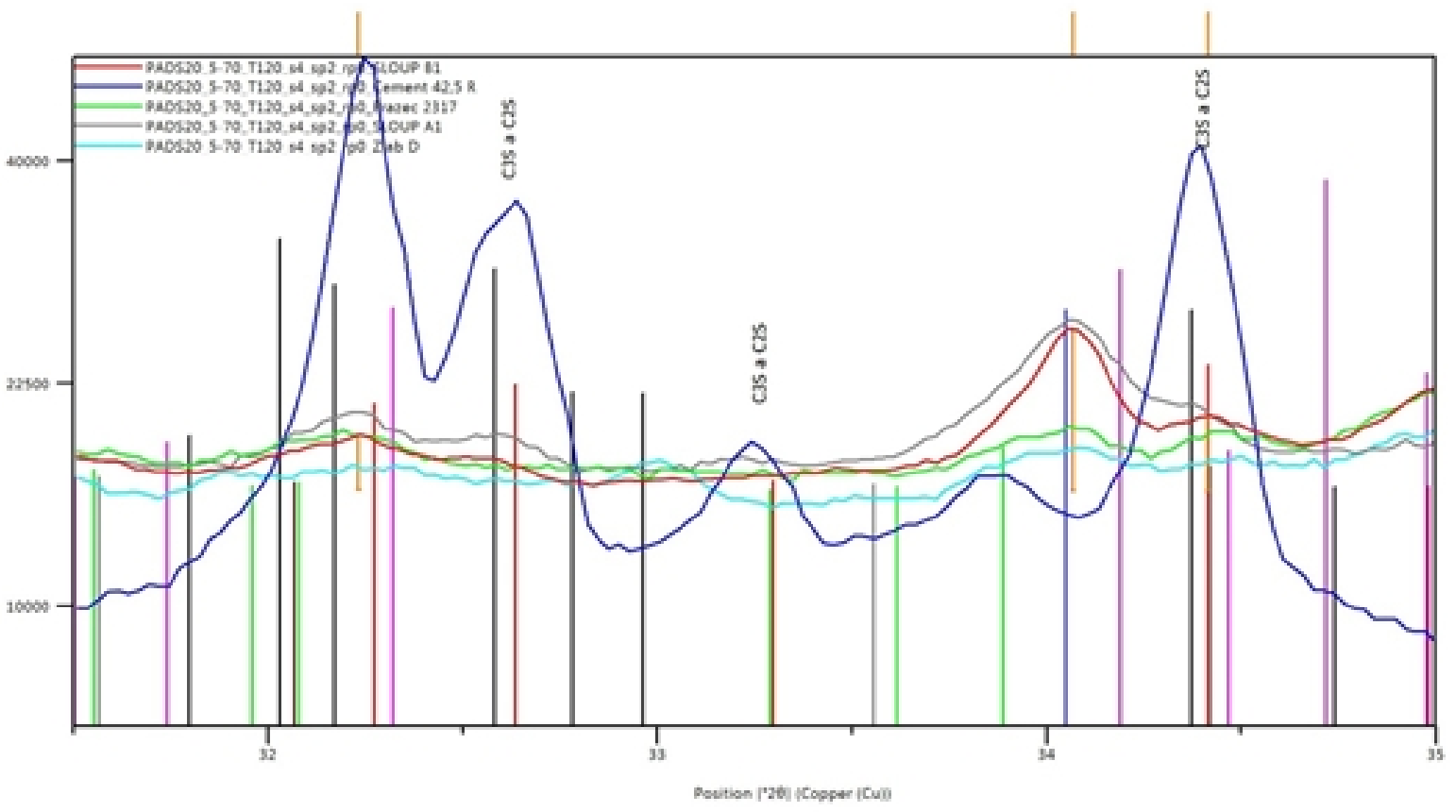

Figure 2. Phases of spectra from XRD analysis.

\begin{tabular}{llcccc}
\hline \multirow{2}{*}{ Materials } & Phase & Fraction & $\begin{array}{c}\text { Average } \\
\text { minimum } \\
\text { grain } \\
\text { size } \\
{[\mu \mathrm{m}]}\end{array}$ & $\begin{array}{c}\text { Average } \\
\text { maximum } \\
\text { grain } \\
\text { size } \\
{[\mu \mathrm{m}]}\end{array}$ & $\begin{array}{c}\text { Shape } \\
\text { index }\end{array}$ \\
\hline \multirow{3}{*}{ Sleeper } & Aggregate & $5-210$ & 41.4 & 61.3 & 1.5 \\
& C-S-H gel + clinker & $3-250$ & 29.1 & 46.5 & 2.0 \\
& Portlandite & $2-15$ & 2.3 & 5.2 & 2.1 \\
\cline { 2 - 6 } Gutter & Aggregate & $3-270$ & 40.3 & 68.9 & 1.6 \\
& C-S-H gel + clinker & $2-220$ & 31.8 & 53.3 & 2.0 \\
\cline { 2 - 6 } Column A & Portlandite & $7-25$ & 9.7 & 15.2 & 1.5 \\
\cline { 2 - 6 } Column Bgregate & C-S-H gel + clinker & $3-50$ & 16.4 & 24.5 & 1.6 \\
& Portlandite & $5-15$ & 10.2 & 14.1 & 1.9 \\
\cline { 2 - 6 } & Aggregate & $2-40$ & 14.8 & 10.3 & 2.0 \\
\hline & C-S-H gel + clinker & $2-50$ & 15.4 & 22.4 & 1.3 \\
& Portlandite & $5-30$ & 10.2 & 30.3 & 1.9 \\
\hline
\end{tabular}

TABLE 2. Results of EDS analysis. 

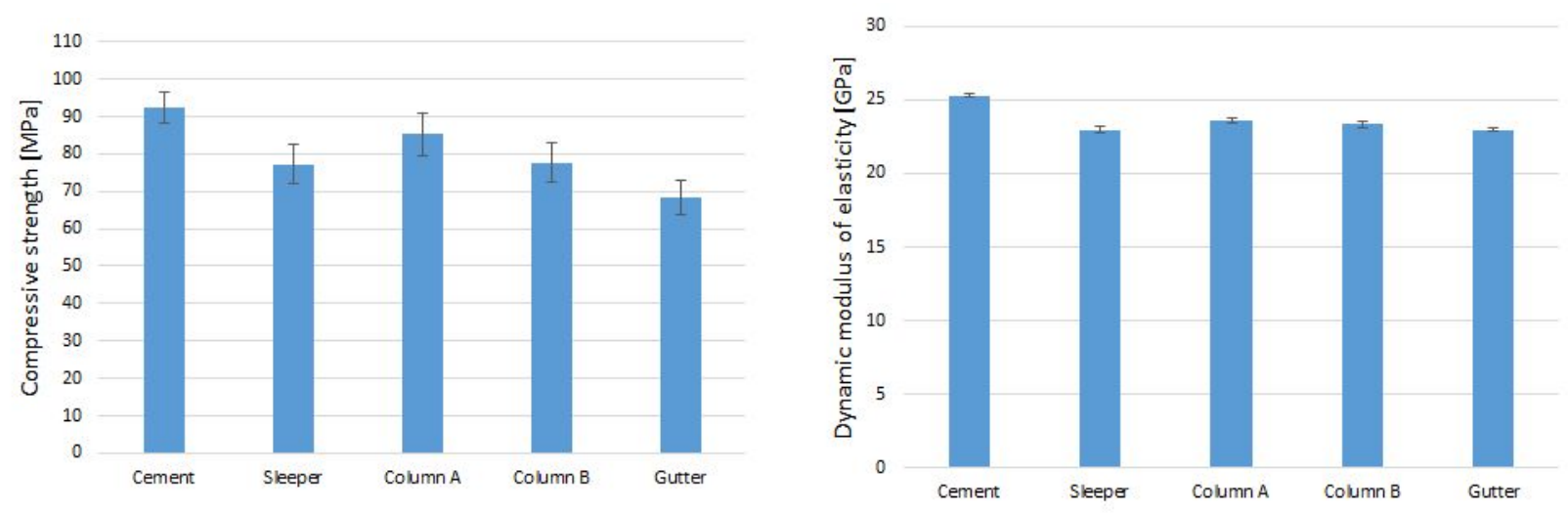

FigURE 3. Mechanical properties of tested composites, compressive strength - left, dynamic modulus of elasticity right.

and the dynamic modulus of elasticity confirm the previous assumptions and that the recyclable is best seen as column A, which reached a strength of $85.37 \pm$ $5.68 \mathrm{MPa}$, ie by $7 \mathrm{MPa}$ less than reference cement and $8 \mathrm{MPa}$ more than other recyclates.

\section{Conclusion}

This work deals with the use of high speed grinding for recycling of old concrete and the direct determination of the potential of the input waste. Four different materials were tested and the results show that:

- none of the recyclates contained excessive amount of harmful substances,

- $\mathrm{pH}$ of the recyclates has a similar value to the reference mixture and thanks to that none of the recyclates significantly influences $\mathrm{pH}$ of the hydration process,

- granulometry has shown that aggregate has a major effect on the resulting granulometry because the gutter, which contained worse aggregate and the column A, where most of aggregate has been removed, have reached the required granulation for activation,

- XRD analysis showed that the largest amount of unhydrated clinker and thus the bigger potential for activation had recyclate from the monolithic structure of the column,

- results of the mechanical tests were confirmed by the previous analysis and that the recyclate from the column A appeared to be the most appropriate because it reached $10 \%$ stronger than the other materials.

In the future, the research will focus on other concrete waste, which will be pre-recycled.

\section{ACKNOWLEDGEMENTS}

This was financially supported by Faculty of Civil Engineering, Czech Technical University in Prague (SGS project SGS16/201/OHK1/3T/11) and by Grant Agency of the Czech Republic (GAČR 17-06771S).

\section{REFERENCES}

[1] EUROSTAT. Waste statistics. http://epp.eurostat.ec.europa.eu/ Accsessed: 2018-09-27.

[2] European Parliament and Council of the European Union. Directive 2008/98/EC of the European Parliament and of the Council.

https://eur-lex.europa.eu/legal-content/CS/TXT/ PDF/?uri=CELEX : 32008L0098\&f rom=LV Accessed: 2018-09-27.

[3] J. R. Jimenez, J. Ayuso, F. Agrela, et al. Utilisation of unbound recycled aggregates from selected CDW in unpaved rural roads. Resources, Conservation and Recycling 58:88-97, 2012.

[4] A. Pasandín, I. Pérez. Overview of bituminous mixtures made with recycled concrete aggregates. Construction and Building Materials 74:151-161, 2015.

[5] F. Rodrigues, M. T. Carvalho, L. Evangelista, J. De Brito. Physical-chemical and mineralogical characterization of fine aggregates from construction and demolition waste recycling plants. Journal of Cleaner Production 52:438-445, 2013.

[6] J. Xiao, W. Li, Y. Fan, X. Huang. An overview of study on recycled aggregate concrete in China (1996-2011). Construction and Building Materials 31:364-383, 2012.

[7] J. Schoon, K. De Buysser, I. Van Driessche, N. De Belie. Fines extracted from recycled concrete as alternative raw material for Portland cement clinker production. Cement and Concrete Composites 58:70-80, 2015.

[8] Z. Shui, D. Xuan, W. Chen, et al. Cementitious characteristics of hydrated cement paste subjected to various dehydration temperatures. Construction and building materials 23:531-537, 2009.

[9] Y. J. Kim, Y. W. Choi. Utilization of waste concrete powder as a substitution material for cement. Construction and building materials 30:500-504, 2012.

[10] F. Tomosawa, T. Noguchi. Integrated design and environmental issues in concrete technology, chap. Towards completely recyclable concrete, p. 263-272. E \& FN Spon, London, 1996. 
[11] Z. Shui, D. Xuan, H. Wan, B. Cao. Rehydration reactivity of recycled mortar from concrete waste experienced to thermal treatment. Construction and Building materials 22(8):1723-1729, 2008.

[12] J. Schoon, L. Van der Heyden, P. Eloy, et al. Waste fibrecement: An interesting alternative raw material for a sustainable Portland clinker production. Construction and Building Materials 36:391-403, 2012.

[13] S. Ahmari, X. Ren, V. Toufigh, L. Zhang.

Production of geopolymeric binder from blended waste concrete powder and fly ash. Construction and Building Materials 35:718-729, 2012.
[14] J. Topič, Z. Prošek, J. Fládr, P. Tesarek. Influence of fineness of recycled concrete powder on the heat evolution and influence of its amount on mechanical-physical properties of cement paste. Waste Forum 2:268-274, 2018.

[15] Z. Prošek, J. Topič, J. Ďureje, J. Trejbal. Comparison between the impact of micronized waste concrete and marble additions on mechanical properties of cementitious pastes. Waste Forum 2:262-267, 2018. 